\title{
LUIS MANUEL FERNÁNDEZ, CARDENAL PORTOCARRERO (1635-1709) UNA VIDA POR ESCRIBIR
}

\author{
POR \\ MANUEL MUÑOZ ROJO ${ }^{1}$ \\ UNED
}

\begin{abstract}
RESUMEN
El cardenal Portocarrero es, sin duda alguna, un personaje imprescindible para conocer los importantes cambios que se van a producir en la monarquía e Iglesia española en el tránsito de los siglos XVII al XVIII. Sin embargo, carecemos de una biografía como tal, una investigación rigurosa del noble, eclesiástico, político y mecenas desde su nacimiento hasta su muerte. La historiografía de los siglos XVII al XX no lo trató de manera muy afortunada y las bibliografías consultadas, incluso las más recientes, siguen distorsionando los datos biográficos del hombre que ocupó la regencia de España por tres ocasiones. En este artículo conocemos nuevos datos de la vida, obra e imagen del cardenal Portocarrero.
\end{abstract}

PALABRAS CLAVE: cardenal Portocarrero; Carlos II; Felipe V; Iglesia y Estado Moderno; Roma; Toledo; Guerra de Sucesión.

\section{LUIS MANUEL FERNÁNDEZ, CARDINAL PORTOCARRERO (1635-1709) A LIFE TO BE WRITTEN}

\begin{abstract}
Cardinal Portocarrero, is undoubtedly, an indispensable personality to know the important changes that will occur in the Spanish Monarchy and Church in the last years of seventeenth century and the first years of eighteenth. However, we lack a biography, a rigorous research of the noble, ecclesiastical, and political and patrons from birth to death. The historiography of the seventeenth to the twentieth century's did not treat him very fortunately and consulted bibliographies, even the most recent, continue to distort the biographical data of the man who occupied the Regency of Spain on three occasions. In this article we can know new information about the life, life's work, and image of Cardinal Portocarrero.
\end{abstract}

KEY WORDS: Cardinal Portocarrero; Charles II; Philip V; Modern Church and State; Rome; Toledo; War of Spanish Succession.

Cómo CITAR ESTE ARTículo / CITATION: Muñoz Rojo, M. 2018. «Luis Manuel Fernández, cardenal Portocarrero (1635-1709) una vida por escribir». Hispania Sacra 70, 142: 543-553. https://doi.org/10.3989/hs.2018.037

$\begin{array}{ll}\text { Recibido/Received } & 25-07-2016 \\ \text { Aceptado/Accepted } & 04-10-2016\end{array}$

\section{LA CONSTRUCCIÓN DEL PERSONAJE}

La construcción del personaje histórico, cardenal Portocarrero, Luis Manuel Fernández Portocarrero y Guzmán, se desarrolla en la historiografía del siglo XVIII por historiadores que erróneamente hemos Ilamado coetáneos, cuando realmente escriben sobre Portocarrero habiendo pasado una distancia considerable en el tiempo y el espacio, pues estos historiadores, comentaristas, narradores o cronistas no vivi-

1 mmunozrojo@gmail.com / ORCID iD: http://orcid.org/0000-0002$3782-6493$ eron directamente los hechos que describen, aún más, no llegaron a conocer directamente al «muy famoso» cardenal Portocarrero. ${ }^{2}$ Son por tanto, historiadores como Vicente Bacallar y Sanna, Francisco Castellví, Nicolás de Jesús Belando y Agustín López de Mendoza los artífices de una primera aproximación a una ridícula personalidad al frente de los destinos de la monarquía hispánica; así lo entendieron ellos y sometieron los acontecimientos al personaje. Es, pues, en

2 1774. The history political and gallant of the famous cardinal Portocarrero Archbishop of Toledo. Done out of French, impreso por W. R. y vendido por J. Nutt. 
la primera mitad del siglo XVIII cuando se trazan los rasgos del cardenal Portocarrero que lo sitúan como un individuo irrelevante y poco preparado para la transición de los Austrias a los Borbones, con los episodios de la redacción del testamento, la intriga y la ambición, y el gobierno propio de Portocarrero en los primeros años del reinado de Felipe V.

Esa configuración distorsionada del personaje Portocarrero arrastra a los historiadores de los siglos XVII a XXI, que lejos de prospectar en los documentos, reproducen con más o menos fortuna lo escrito por los anteriores y singularmente por los citados, con honrosas excepciones. Pretendemos en este artículo aportar una lectura revisada a partir de fuentes primarias, que nos clarifican y redefinen la personalidad del cardenal Portocarrero. Manuscritos tales como los conservados de su infancia en los archivos de protocolos notariales en Posadas, el archivo familiar conservado en gran parte en el Archivo Histórico Provincial de Zaragoza y las abundantes fuentes que nos llevan al eclesiástico en el Archivo Capitular y el Archivo Diocesano de la ciudad de Toledo. Para conocer la década que pasó en tierras italianas, así como su relación con la Santa Sede, son fundamentales el Archivo Secreto Vaticano, Archivo Histórico Nacional y Archivo General de Simancas. La documentación sobre el cardenal Portocarrero es numerosa y dispersa por archivos y bibliotecas locales, regionales, nacionales e internacionales.

Estos documentos contribuyen a un mejor conocimiento de la gran personalidad y talla política, eclesiástica y humanística del cardenal Portocarrero, que nos obligarán a trazar próximamente un trabajo de biografía revisionista y tridimensional de su vida, su obra y su imagen. Dada la magnitud de fuentes primarias, con manuscritos relevantes para estudiar la trayectoria personal del cardenal, un considerable material de fuentes secundarias, con documentos impresos, muy próximos a los acontecimientos que describen y una amplia y heterogénea bibliografía que abordan capítulos protagonizados por Luis Manuel Portocarrero en asuntos muy variados, procuraremos en este artículo clarificar su formación universitaria, examinar los tres expedientes de limpieza de sangre, su acceso al cardenalato y nombramientos posteriores en la curia romana, su pragmatismo político, los tres nombramientos de gobernador, su lealtad al rey Felipe $\mathrm{V}$ y todo el proceso de su muerte y sepelio; así como, ordenar esa documentación, sistematizar la información, discernir el hecho real frente a la conjetura u opinión que se desliza con bastante naturalidad, corregir errores biográficos repetidos hasta la saciedad y ofrecer una visión de conjunto de la vida, obra e imagen del cardenal Portocarrero que, sin duda, será bien distinta de la que hemos conocido hasta el momento, fruto de una historiografía continuista en los derroteros de la intriga, la decadencia y la tergiversación de los hechos. Afortunadamente, algunos historiadores han iniciado un proceso de revisión de la figura del cardenal Portocarrero que nos ayuda en esta línea investigadora en pro de construir la biografía del hombre que tuvo en sus manos el poder eclesiástico y político en la transición entre los siglos XVII al XVIII; historiadores como Luis Antonio Ribot García, Antonio Ramón Peña Izquierdo, África García Fernández, Alfredo González Rodríguez, Adolfo Hamer Flores o José Manuel de Bernardo Ares, quien ha coordinado El Cardenal Portocarrero y su tiempo (16351709), recopilación de los trabajos expuestos y debatidos en las V Jornadas de Historia "Cardenal Portocarrero» ${ }^{3}$, y muchos más, que a la luz de sus tesis, estudios y publicaciones siguen revelando aspectos inéditos y análisis certeros sobre la gran talla política del cardenal Portocarrero, que han renovado la historiografía de este personaje y nos han permitido continuar esta labor investigadora en territorios desconocidos que gracias a analizar documentos manuscritos, sistematizar la bibliografía y contrastar el volumen de datos inconexos que circulan sobre el cardenal Portocarrero, permiten la construcción de un trabajo de naturaleza biográfica.

\section{LA VIDA Y OBRA}

Luis Manuel Fernández Portocarrero Mendoza y Luna y Guzmán nació el 8 de enero de 1635 en el palacio de los condes de Palma, en la villa de Palma del Río; segundo hijo varón de los marqueses de Almenara, Luis Andrés Fernández Portocarrero Mendoza Luna y Leonor de Guzmán Enríquez Portocarrero. De aquel matrimonio nacieron otros tres hermanos, Fernando Luis ${ }^{5}$, IV conde de Palma, Inés María y Agustina ${ }^{6}$ quienes contrajeron matrimonio con importantes nobles de la España de mediados del siglo XVII.

Luis Manuel pasó su infancia en Palma del Río y a la edad de catorce años, su madre y su hermano mayor, el conde de Palma, solicitaron al papa Inocencio X las bulas o letras pontificias de coadjutor con derecho a sucesión en el deanato de la catedral de Toledo, cuyo titular era su tío abuelo Antonio Fernández Portocarrero7; la bula resignatio

\footnotetext{
3 De Bernardo Ares 2013. Los trabajos de biografías estelares, en los que participamos, forman parte del corpus documental de este artículo.

4 ACT (Archivo Capitular de Toledo), leg. 308. Expediente de limpieza de sangre. La fecha de nacimiento del cardenal Portocarrero ha sido confundida con la fecha del nacimiento del primogénito de los marqueses de Almenara, Luis Esteban Manuel Antonio de los Reyes, bautizado el 8 de enero de 1628, quien hubo de fallecer al poco tiempo. Otras fuentes sitúan el nacimiento en septiembre o diciembre de 1629. El hermano mayor y futuro conde nació en 1630, pues su muerte a los 19 años en 1649 está ampliamente documentada. Por tanto, la partida de bautismo del 8 de enero de 1635 es el primer documento contrastado del nacimiento del cardenal del que existen referencias en otros documentos posteriores encargados por el propio cardenal. Real Academia de la Historia, (a partir de ahora RAH), M. 115, f. 256. Partida de bautismo del cardenal Luis Manuel Fernández Portocarrero y Guzmán.

AHPZ (Archivo Histórico Provincial de Zaragoza), leg. P. 001546/0008 Genealogía y títulos presentados por el cardenal Portocarrero para la orden del Sancti Spiritu, s.n. Fernando Luis Fernández Portocarrero y Guzmán primogénito y heredero del título de marqués de Almenara por muerte de su padre en 1636 y IV conde de Palma por muerte de su abuelo el III conde de Palma en 1639. Casó con Antonia de Moscoso y Osorio con quien tuvieron un único hijo el 7 de marzo de 1649, Luis Antonio Tomás Fernández Portocarrero y Moscoso, V conde de Palma, tras fallecer su padre en agosto de1649.

6 APNP (Archivo de Protocolos Notarial de Posadas). Leg. 160, ff. 93r-99v, 24 de febrero de 1650, Capitulaciones del matrimonio de Inés María Portocarrero y Guzmán con Juan Fernández Portocarrero y Pacheco en la villa de Palma. Esta hermana contrajo tres matrimonios y no tuvo descendencia. La segunda hermana, Agustina Fernández Portocarrero contrajo matrimonio en 1663 con el marqués de Oraní, Isidro Silva de Portugal con quien tuvo descendencia.

7 APNP, leg. 106. ff. 19r-20v, Palma, 27 de enero de 1648. Leonor de Guzmán, marquesa viuda de Almenara y su hijo Fernando Luis Fernández Portocarrero, conde de Palma otorgan poder a José González de la catedral de Toledo para solicitar las bulas o letras apostólicas de coadjutoría del deán de Toledo para Luis Fernández Portocarrero.
} 
in favoren le fue concedida en mayo de 1649 previo pago a la Dataría Apostólica ${ }^{8}$; esto suponía recibir la preciada bula que aseguraba la sucesión en el cargo de una élite social que controlaba los beneficios eclesiásticos. Todas las fuentes coetáneas aseguran que intervino para lograr la bula de coadjutor el nuevo embajador de España en Roma Rodrigo Díaz de Vivar Sandoval Hurtado de Mendoza y Luna, VII duque del Infantado, familiar del joven eclesiástico, pero el embajador no entró en Roma hasta el 20 de enero de 1650:

Adultiorem aetatem pene ingreftus, precibus $D$. Ducis de Infantado cum fotore patruela Ludovici nupri, \& Romae apud Innocentium X. Regis Catholici Oratoris, gratiam Coadiutoriae Decanatus Ecclesiae Toletanae Hifpaniarum Primatis obtinuit, praeuio confenfu $D$. Antonii Fernandez de Portocarrero illius patrui, \& Decani, qui per fpatium triginta \& vnius annorum, magna in negotiis expediendis dexteritate exemplo, omniumque applaufu illam gubernauit, [...]. ${ }^{9}$

En 1649 el joven Portocarrero inicia un viaje sin retorno hacia Toledo para comenzar en las labores formativas de un pretendiente a la carrera eclesiástica. El 31 de mayo de 1651 fallece el veterano deán y asume el deanato Luis Manuel Fernández Portocarrero con tan solo dieciséis años. Previamente hubo de pasar su primer expediente de limpieza de sangre, habrá dos más, que evidentemente superó:

En la villa de Palma a trece días del mes de noviembre de mil y seiscientos y cincuenta y un años, el doctor don Francisco Fernández de Córdoba, canónigo de la Santa Iglesia de Toledo, primada de las Españas, juez comisario nombrado por los ilustrísimos señores Deán y Cabildo de dicha Santa Iglesia para hacer información de las cualidades, ascendencia y Limpieza de don Luis Fernández Portocarrero para haber de ser admitido por Deán de la dicha Santa Iglesia conforme a su estatuto en virtud de su comisión y del poder de la parte [...].10

El joven deán entró rápidamente en contacto con la Corte de Felipe IV, quien le nombró Sumiller de Cortina dando acceso directo al palacio real al descendiente de tan ilustre linaje de Bocanegra y Portocarrero. En mayo de 1655, año jubilar, el rey Felipe IV nombró al deán Portocarrero como su representante oficial para realizar la ofrenda al santo patrón de España. La comitiva del deán se trasladó hasta la catedral de Santiago de Compostela llevando como regalo unos hermosos tapices obsequio del rey. El cabildo compostelano recibió con todos los honores al visitador real, quien leyó una carta de puño y letra del monarca lamentando por razones de sus ocupaciones no realizar personalmente la visita. ${ }^{11}$

8 ACT, Actas Capitulares, lunes 17 de julio 1651, "Este dicho día fueron presentadas por parte del señor don Luis Fernández Portocarrero Bulas del tenor siguiente... Datis Roma apud Sanctam Mariam maio ren anno Incarnationis Dominice millessimo sexcentes mo quadragesimo nono sexto nonas May...».

9 Chacón y Oldoini 1677: 789.

10 ACT, leg. 308. Expediente de limpieza de sangre. El juez informante Francisco Fernández de Córdoba recorre las ciudades de Madrid, Guadalajara, Sevilla y la villa de Palma (Córdoba) para redactar el expediente de limpieza de sangre.

11 BNE (Biblioteca Nacional de España), mss. 18654/60 Recibimiento que se hizo al señor Deán de Toledo en nombre de S.M. vino a visitar esta Santa Iglesia en 9 de este mes de junio de 1655 entró en esta ciudad el señor don Luis Fernández Portocarrero, deán de la Santa Iglesia de Toledo, sumiller de cortina del rey Felipe IV.
A su regreso obtendría un nuevo beneficio como canónigo de la catedral de Toledo en una canonjía de designación real, el canonicato vacante número veintinueve, aumentando sus recursos mientras estudiaba la licenciatura de derecho canónico y civil en la Universidad de Toledo:

In celebri, \& insigni Academia Toletana, (quae una est ex quatuor maioribus Universitatibus Hispania) Ludovicus literaria, studia prosequens, diversos Actus, Conclusionum, \& Lectionum publice, \& secretè habuit; in eadem Universitate Laurea licentiatus in utroque lure cómunt ómnium suffragio dignisimè fuit insignitus, cuius inclytae prosapiae, \& signanter ipsiusmet Ludovici merita Philippus IV. prae oculis habens, in Regio Palatio, munere Velaminis, vulgo Sumiller de Cortina nùcupato, eum condecoravit. Indè Visitato em Regium Templi, \& Corporis D. Iacobi Hispaniarum Patroni [...]. ${ }^{12}$

El deán Portocarrero completada su formación universitaria recibiendo las órdenes sagradas mayores el año de 1663. ${ }^{13}$ Su carrera eclesiástica discurre junto al arzobispo y cardenal Baltasar Moscoso y Sandoval, con quien comparte la celebración de un sínodo diocesano, experiencia eclesial que influirá en gran medida en el joven deán.

Un nuevo giro tomará la vida del deán Luis Manuel Fernández Portocarrero el 20 de diciembre de 1661 cuando fallece su madre, Leonor de Guzmán, quien en su testamento confió a este la administración del estado de Palma y tutela del pequeño sobrino, Luis Antonio Tomás Fernández Portocarrero, $\mathrm{V}$ conde de Palma. ${ }^{14}$ Portocarrero traslada hasta Madrid a su hermana Agustina, a quien casará con el Marqués de Oraní, y a su sobrino el conde de Palma, que contraerá matrimonio en 1667 con su prima hermana Leonor de Moscoso. Esta unión estratégica de todos sus miembros familiares directos con grandes linajes de España, van a posicionar al deán Portocarrero en las futuras crisis institucionales tras la muerte del rey.

En septiembre de 1665 fallecen el rey Felipe IV y el arzobispo de Toledo, Baltasar Moscoso y Sandoval, ocupando la administración de la sede vacante el deán Portocarrero, quien además fue elevado a vicario general de la diócesis hasta la incorporación del nuevo arzobispo de Toledo, Pascual de Aragón. El cardenal Aragón llega para formar parte de la junta de regencia con la reina madre Mariana de Austria, en la minoría de edad de Carlos II. Este cambio en la sede primada permite al deán Portocarrero lograr la capellanía de la reina Catalina en la capilla de los Reyes Nuevos con su correspondiente segundo expediente de limpieza de sangre:

Nos. el Vicecapellán Mayor y capellanes de la Real capilla de la Serenísima Reina Señora Catalina sita y con frente con la de los señores Reyes nuevos de la Iglesia de Toledo Primada de las Españas por cuanto en esta Real Capilla hay estatuto de limpieza confirmado por autoridad Real cerca de las cualidades que han de tener los que hubieren de ser admitidos por capellanes de ella; y ahora el Sr. D. Luis Fernández Portocarrero Deán y Canónigo de Nuestra Santa Iglesia ha pedido ser admitido a la Capellanía Mayor de esta Real Capilla por estar

\footnotetext{
12 Ídem.

13 ADT (Archivo Diocesano de Toledo), Libro de órdenes, 1663.

14 APNP, leg. 313, ff. 358r-359v. Escritura de tutoría otorgada por Leonor de Guzmán a favor de su hijo Luis Manuel Fernández Portocarrero.
} 
vaca por exaltación a la silla arzobispal de Toledo del Ministro Señor Cardenal Aragón [...]. ${ }^{15}$

En el contexto de la crisis política de 1668-1669, con el enfrentamiento del hermanastro del rey Juan José de Austria contra el valido de la reina, el jesuita Everardo Nithard, el nuevo hombre fuerte del reino coloca en la terna de candidatos a la púrpura al deán Luis Manuel Fernández Portocarrero frente a las pretensiones de la reina de situar a su confesor Nithard. Clemente IX nombró cardenal in pectore a Portocarrero el 5 de agosto de 1669, y confirmó ese nombramiento en el consistorio del 29 de noviembre de ese año:

29 Nov. 1669 hora 20 per cursores fuit intimatum consist. Secretum in pal. Quirinali pro hora 21. Ad pal. Quirinali convalaverunt em. Car.les praesentes in Curia uno tamen excepto em. Chisio, et hora 22 ingressi sunt cubiculum, in quo decumbebat S.S. indutus rochetto mozzetta et super eam stolam habens. Clauso igitur consist. Post nonnulla verba card.lem declaravit Ludovicum Fernández de Portocarrero, Hispanum eccl.ae Toletan. decan., absentem. Quem in pectore reservaverat 5 Aug. $1669 .{ }^{16}$

Se ha llegado a afirmar que la reina Mariana de Austria ofreció al cardenal Portocarrero, tras su elección como cardenal, el arzobispado de Granada para apartarlo de la Corte, pero esto no fue posible en esta fecha pues el arzobispo de Granada, José de Argáiz, murió en 1667 y en 1668 admitió la mitra Diego Escolano y Ledesma ${ }^{17}$, quien reconoció que aquella sede tuvo muchos ofrecimientos, entre ellos Portocarrero, que no la aceptó:

A sus cincuenta y nueve años, Escolano llegó a la sede granadina de rondón, pues la terna propuesta el 28 de junio de 1667 para cubrir la vacante dejada por muerte de D. José Argáiz, todos se excusaron, por su orden de aceptar la mitra: el Obispo de Plasencia, D. Rodrigo Riquelme por llevar dos años en el cargo y ser muchas las necesidades de su diócesis; el Obispo de Osma, por ser muchos sus empeños y no quererlos mayores, y el deán de Toledo, D. Luis Fernández Portocarrero, sin duda por aspirar a algo mejor. ${ }^{18}$

El propio arzobispo Escolano reconocía en el Memorial a la Reyna... ${ }^{19}$, la tardanza en la publicación de su nombramiento por saber que se había ofrecido el arzobispado a otros y todos renunciaron o abiertamente no aceptaron, o tal vez dudaron, pues al menos a Granada llegó un cuadro con la imagen de Portocarrero como nuevo arzobispo de aquella ciudad andaluza pero la pintura fue rebautizada como arzobispo Escolano. ${ }^{20}$

El papa moría el 9 de diciembre de 1669 y definitivamente, el flamante cardenal Portocarrero marchó a primeros de año hacia Roma, con evidente retraso, para participar en el cónclave donde se estaba eligiendo al próximo pontífice. El cardenal Portocarrero ingresó en la Capilla Sixtina el 23 de abril de 1670 siendo elegido nuevo santo padre, Clemente $\mathrm{X}$, cardenal Altieri. Ciertamente, el cardenal Portocarrero

15 ACT, leg. 308. Expediente de limpieza de Luis Manuel Fernández Portocarrero instruido por el cabildo de Toledo para la capellanía de la capilla de la Reina Catalina, Toledo, 10 de junio de 1666.

16 ASV (Archivo Secreto Vaticano), Archivo Consistorial, Acta Camerarii, 22, f. 30.

17 Burillo Loshuertos 1997: 124.

18 López-Guadalupe Muñoz 2010: 311.

19 Escolano y Ledesma 1669: 2.

20 Casteñeda Becerra 2006: 403-412. participó en el cónclave pero aún no había recibido ni el capelo ni el título correspondiente. Fue el nuevo pontífice quien en dos consistorios muy seguidos, los días 17 y 19 de mayo de 1670 le entregase el capelo y el título. ${ }^{21}$ El día 17 de mayo en consistorio público, el cardenal Portocarrero recibió de las manos de Clemente $\mathrm{X}$, el anillo y el capelo rojo, propios de su nueva dignidad de príncipe de la Iglesia; en un segundo consistorio privado el día 19 de mayo, le concedió el título de cardenal presbítero de Santa Sabina del Monte Aventino junto al convento de padres dominicos. Además el nuevo pontífice nombró a Portocarrero miembro de la curia romana con responsabilidades en las Congregaciones del Santo Oficio, Obispos y Regulares, Concilios y Sagrada Congregación de Ritos, iniciando un intenso trabajo eclesial y político al servicio de la Iglesia y de la monarquía católica.

El cardenal Portocarrero se instaló primeramente en la embajada de España como huésped de honor del embajador en Roma, marqués de Astorga, y desde el 3 de mayo de 1670 residirá en un histórico palacio, que había servido como embajada española, el palacio Cupis en la plaza Navona, muy cerca de la iglesia de Santiago de los españoles. ${ }^{22}$ En esta prestigiosa y referencial iglesia hispana en Roma se encontraba la sede de la archicofradía de la Resurrección de la cual el cardenal Portocarrero fue miembro muy activo. Será en la Roma de Bernini y Borromini donde entró en contacto con la vida profana y religiosa de la Corte romana y donde pudo entablar amistad con la reina Cristina de Suecia, la princesa de los Ursinos, los príncipes y nobles italianos al servicio de la Corona de España, los cardenales nepotes y los vinculados a los reyes y emperadores, los virreyes españoles en Nápoles y Sicilia, así como aquellos que fue conociendo en España, y que ahora reencontraba en Roma, como a Juan Everardo Nithard, nuevo embajador provisional, a quien el papa Clemente X le nombrará cardenal en 1672, dada las presiones de la reina regente, Mariana de Austria, situación que alimentará tensiones entre príncipes italianos, la curia romana y el omnipresente cardenal Portocarrero. ${ }^{23}$

El cardenal Portocarrero, por su condición de miembro de la Congregación de los Ritos y procurador de causas de canonización, participó activamente en el reconocimiento de los santos y beatos hispanos desde 1671 a 1675; Fernando III el Santo, san Luis Beltrán, san Francisco de Borja y santa Rosa de Lima, primera santa de las Indias Occidentales; los beatos Juan de la Cruz y Francisco Solano; así como el proceso de la venerable sor María Jesús de Ágreda. También promovió la causa de canonización del cardenal Cisneros, regente de España e inspirador de la línea política y eclesiástica que el cardenal Portocarrero defenderá para la sucesión de la Corona española. ${ }^{24}$

21 ASV, Archivo Consistorial, Acta Camerarii, 22, ff. 33-35.

22 Esténaga y Echevarría 1929: I, 362.

23 Para la etapa romana consideramos fundamental la lectura de los trabajos de los historiadores: Barrio Gozalo 2009: 237-273, 2010 y 2013; Carrió Invernizzi 2008; Lozano Navarro 2010: vol. 7, n. 20, 1-27 y 2013: 12-23; Marqués 1983.

${ }^{24}$ Congregatione sacrorum rituum siue Eminentissimo... Car. Portocarrero Toletana Beatificationis \& Canonizationis... Francisci Ximenez de Cisneros... Positio super dubio An constet de validitate \& releuantia processus super inquisitione in genere, vt deueniendum sit ad inquisitionem in specie, \& remissoria super concedenda. In casu \&c. - Romae: Ex Typographiae Reuerendae Camerae apostolicae, 1672. 8, 2, [1] en bl., 3-6, 10 [i.e. 4], 28; Fol. 
El cardenal Portocarrero asumió fielmente las directrices de la monarquía católica hispánica impulsando la devoción a la Inmaculada Concepción tal como se desprende de su impronta mariana en el colegio español de Bolonia del que fue cardenal protector; años más tarde, el cardenal Portocarrero será nombrado presidente de la Real Junta de la Inmaculada.

En su condición de cardenal protector de España realizó el acostumbrado viaje al santuario de la casa de Loreto acompañado de un amplio séquito e igualmente visitó la basílica de Asís donde recibió el hábito de la orden tercera franciscana:

Alli 10-di. Aprile 1671. I’ Emo Sig. Cardinal Lodovico Fernandez Portocarrero si vesti dell' abito del Terz' Ordine in S. Cappella della Porziuncola, e fece anche professione di osservare la Regola di detto Terz' Ordine. Lo stesso abito insieme con lui presero sette nobilissimi tutti Cavalieri di Spagna [...]. ${ }^{25}$

De manos de Clemente $X$ recibió numerosas reliquias de santos mártires que mandó a diferentes templos de España, regalos que siempre eran muy agradecidos por los cabildos catedralicios, los conventos de religiosos y religiosas y los templos donde llegaron los restos tan venerados. En suma, el cardenal Portocarrero vivía aprendiendo el arte de la escuela diplomática vaticana, entrando en contacto con las variadas facetas de la religiosidad barroca y las singulares tradiciones hispanas que se ejecutaban con gran solemnidad en Roma, así como gozando de los placeres mundanos que le ofrecía la vida romana:

En el caso de Portocarrero también encontramos la misma tensión entre la abnegación religiosa y lo mundano, pero en su caso los indicios de gusto por el fasto de las cortes romanas son muchos más numerosos y significativos que en Aguirre. Algunos testimonios de la época confirman que Portocarrero frecuentaba las conversazioni e divertimenti como las que se celebraban en el salón Orsini [...]. ${ }^{26}$

Un cardenal implicado en la recepción brillante de los representantes de la monarquía de Carlos II o en la celebración de la solemne procesión de la cofradía española de la Resurrección el Domingo de Pascua:

In tal senso superba e memoranda rimane la festa notturna del 25 aprile 1675 celebrata a Piazza Navona, tutta recinta di travi festonati d'alloro e splendidamente illuminata. [...] Un 'altra macchina era posta sopra la fontana davanti al palazzo del cardinale Lodovico Fernández Portocarrero, simile alla precedente di grandezza, altezza e larghezza; ma la statua che aveva in cima, rappresentava la Vergine. ${ }^{27}$

Por otro lado, el cardenal Portocarrero participa en una de las fiestas más populares de Roma, organizadas tradicionalmente por la embajada de España, acto que consistía en la presentación al papa, la víspera de san Pedro, de una jaca blanca con un vaso de plata con siete mil escudos de oro por el tributo feudatario que el reino de Nápoles entregaba anualmente al sumo pontífice. La

\footnotetext{
25 Di Cannara 1780: 82.

26 Domínguez Rodríguez 2014: 40.

27 Gligora y Catanzaro 2015: 91
}

ceremonia la ejecutaba un príncipe italiano al servicio de la Corona de España, y a la misma acudían la aristocracia romana e italiana junto al embajador de España y el embajador protector, el cardenal Portocarrero. Durante la embajada interina de Juan Everardo Nithard (1671-1677) estuvo rodeada de polémicas y desaires, pues eran muchos los que no aceptaban a este embajador y hubieran preferido al cardenal Portocarrero de noble familia.

El cardenal Portocarrero vivió directamente los solemnes actos del año jubilar de 1675 convocados por el papa Clemente X. Portocarrero fue uno de los tres cardenales elegidos por el pontífice para realizar la clausura del año santo, liturgia que llevó a cabo solemnemente en la basílica de Santa María la Mayor. Para la ocasión, el cardenal encargó una paleta de plata con su escudo de armas que usó en el oficio religioso y deseó que aquel día de diciembre de 1675 quedara registrado en un libro relación editado en Sevilla. ${ }^{28}$

En 1676 se produce una nueva crisis política en España, un vez más abanderada por Juan José de Austria, en esta ocasión directamente contra el valido de la reina regente, Fernando de Valenzuela y Enciso. De resultas de este enfrentamiento Valenzuela será expulsado de España, la reina madre confinada en el Alcázar de Toledo y el gobierno asumido por el hermanastro del rey. En Roma, el papa Clemente $X$ fallece el 22 de julio de 1676. Tras su muerte se inicia un cónclave sumamente importante para las coronas europeas donde el emperador germánico, el rey cristianísimo de Francia y el rey católico de España, desean un pontífice fiel a sus intereses. El cardenal Portocarrero junto al cardenal Nithard tiene un papel fundamental para lograr un candidato que agrade en Madrid. Con ese empeño, llega a Roma desde Milán el joven conde de Melgar, futuro Almirante de Castilla con instrucciones de la Corte hispana. El elegido es Benedetto Odescalchi, que reinará la Iglesia como Inocencio XI:

¿Se trata realmente de una victoria española? Podría parecerlo. De hecho, algunos autores afirman que es una victoria personal de Portocarrero, de quien el cardenal Odescalchi habría sido el candidato encubierto desde 1670. En mi opinión, habría que matizar estas dos afirmaciones al tratarse también de un triunfo del escuadrón volante y de la presión ambiental. ${ }^{29}$

El 31 de diciembre de 1676 se expide el real despacho nombrando al cardenal Portocarrero, virrey de Sicilia interino, en un contexto de guerra, dado que la población de Mesina se ha revuelto contra el rey de España, con fuertes apoyos de la armada francesa. El 12 de mayo de 1677 llega a la isla con la fuerte determinación de acabar con la insurrección:

El cardenal Portocarrero llegó a la isla el 12 de mayo y asumió automáticamente todos los poderes del virrey, a pesar del desagrado de San Martino. El cardenal Portocarrero le ordenó que le informara sobre la situación militar, pero el marqués escribió al rey, alegando que un capitán general no tenía por qué obedecer a otro. ${ }^{30}$

\footnotetext{
28 Cabezas 1676. Se conserva un ejemplar en la Universidad de Sevilla, fondo antiguo, sig. A 111/101 (11).

29 Lozano Navarro 2010: vol. 7, n. 20, 26.

30 Ribot García 2002: 283.
} 
Muchos son los que consideran que el cardenal Portocarrero no está preparado militar y políticamente para gobernar este virreinato. Su destino, autorizado por el nuevo papa, va reforzado con el nombramiento de consejero de Estado, esto supone el salto a la máxima institución consultiva y gubernativa de los reinos de España. El cardenal Portocarrero dotado de un carácter enérgico asume su nueva responsabilidad con decisiones temerosas pero que le darán éxito militar logrando aplacar la revuelta.

Pero el destino, Portocarrero hubiera dicho la Providencia, se vuelve a cruzar en su vida, dado que el 28 de septiembre de 1677 fallece el arzobispo de Toledo, Pascual de Aragón. Carlos II, con la anuencia del nuncio Savo Millini, nombra para la sede vacante al cardenal Portocarrero. El 20 de diciembre de ese año, el papa Inocencio XI concede la bula de nombramiento al nuevo arzobispo Luis Manuel Fernández Portocarrero quien va a regir la sede primada de las Españas, el más rico de los ocho arzobispados españoles. ${ }^{31}$ La toma de posesión se hará por poderes y la consagración episcopal tuvo lugar en enero de 1678 en la catedral de Palermo. Mientras en Toledo, el vicedeán Pedro Portocarrero y Guzmán tomaba posesión del arzobispado en nombre de su pariente Luis Portocarrero y Guzmán.

El virrey de Sicilia, Consejero de Estado y Arzobispo de Toledo, cardenal Portocarrero culminó su breve virreinato en marzo de $1678 .{ }^{32}$ El gobierno de Juan José de Austria lo nombra embajador extraordinario en Roma, una forma de prolongar su estancia romana y presionar al pontífice sobre determinados intereses españoles en el Mediterráneo. El cardenal Portocarrero regresó a Nápoles y de allí partió a Castel Gandolfo. En mayo de 1678 entró en Roma donde fue recibido con honores de embajador. Pero en la primavera de 1679, un año después, se despide de Inocencio XI cumplimentando su primera visita ad limina, un mero trámite de cortesía, tal como ha estudiado Ángel Fernández. ${ }^{33}$ Culmina el cardenal Portocarrero su década italiana que completa con un elaborado viaje de regreso que le servirá como entrada triunfal en los reinos de España. ${ }^{34}$

En junio de 1679 es recibido en primer lugar por el rey Carlos II, mayor de edad desde 1675, y por su hermanastro Juan José de Austria, quien conoce a Portocarrero desde sus años de deán; seguidamente se dirige a Toledo para entrar solemnemente como nuevo arzobispo primado de España. Se podría afirmar que regresa a casa. Pero en Toledo vive una inquilina muy especial, la reina madre Mariana de Austria en un exilio forzoso apartada de la Corte y de su hijo el rey Carlos II. En septiembre fallece Juan José de Austria pero antes, y con el aplauso del cardenal Portocarrero, se ha elegido una candidata para esposa y reina, María Luisa de Orleans, una princesa de la Corte de Francia.

La década de los ochenta representa en la vida y obra del arzobispo de Toledo una preocupación constante por hacer patente una pastoral de profunda renovación del estamento eclesiástico y de las costumbres religiosas de la mayor

31 AGS (Archivo General de Simancas), PTR, leg. 63, Doc. 32. Bula de Inocencio XI al cardenal Portocarrero, elegido arzobispo de Toledo.

32 Peña Izquierdo 2004

33 Fernández Collado 2001-2002: 49-102.

34 ADT IV/3133, Información de cómo fue recibido el cardenal Portocarrero en los lugares por donde pasó cuando vino de Roma desde la raya que divide los reinos de España y Francia. archidiócesis española. Ello implica decretos, pastorales y bandos inspirados en los postulados del Concilio de Trento, las encíclicas y breves papales así como la defensa de los derechos de la Iglesia frente a los privilegios del Patronato Real y las órdenes fiscales promulgadas por los ministros de Carlos II.

El arzobispo Portocarrero recorre la diócesis, reconoce la escasa formación del clero y las costumbres profanas y nulo conocimiento de la doctrina católica por parte de la población. Con este panorama, convoca el Sínodo Diocesano de 1682, una apuesta decidida por la revisión programática de la Iglesia toledana. ${ }^{35}$ De su importancia nos habla como durante siglos sus constituciones rigieron la vida eclesiástica diocesana.

Portocarrero se empleó a fondo en la condena de las corridas de toros $^{36}$, en el uso indebido de los templos ${ }^{37}$, en la carencia de formación cristiana ${ }^{38}$, es decir, fueron años centrados especialmente en su labor de arzobispo de Toledo, primando la acción pastoral, el mejor conocimiento de su feligresía y el intento de cambiar hábitos y mejorar la vida del estado eclesiástico con la voluntad de impedir más ordenaciones de sacerdotes sin la suficiente preparación o no permitir más fundaciones de conventos en Madrid y otras localidades de la enorme diócesis. Sobre este último particular, fundaciones conventuales, ha quedado registrado un capítulo donde se cruza su voluntad firme de impedir nuevos monasterios y un «milagro» obrado por santa Teresa de Jesús para saltarse la rígida prohibición de más conventos. ${ }^{39}$

Pero fue en la defensa de los derechos de la Iglesia frente a los intentos de los ministros de Carlos II de controlar la fiscalidad tradicional del poder eclesiástico donde el arzobispo Portocarrero se empleó con todas sus energías recurriendo a la excomunión de quienes osasen entrometerse en la jurisdicción administrativa del poderoso poder eclesial. Sus enfrentamientos directos con los ministros de Carlos II fueron reconducidos hábilmente por la Santa Sede, tal como ocurrió en $1686 .{ }^{40}$

El cardenal arzobispo Portocarrero se mostró enérgico y a la vez diplomático en la resolución de conflictos con la Corte, el priorato de san Juan, la Nunciatura Apostólica o con la misma Santa Sede. Durante todo su pontificado como arzobispo primado de las Españas, priorizó en la defensa de los intereses de la Iglesia o derechos y privilegios que le correspondían por su dignidad de primado. Reclamó diplomáticamente ante Roma su status frente al nuncio Savo Millini, o su jurisdicción como señor de las villas donde estaba asentado el priorato de san Juan, que siempre quiso

\footnotetext{
35 BNE, Synodo Diocesana del Arzobispado de Toledo, 1682.

36 BNE, mss. 10422. Consulta que el cardenal Portocarrero hizo en 25 de septiembre de 1680 a Su Majestad representándole cuanto convenía la prohibición de la fiesta de los toros.

$37 \mathrm{BNE}, \mathrm{VE} / 207 / 27,1681$. Edicto en que se manda prohibir el almorzar, comer, merendar, beber, tomar chocolate $u$ otros cualesquiera refrescos o colaciones en las iglesias, capillas, ermitas... Nos don Luis Manuel, Cardenal Portocarrero.

$38 \mathrm{BNE}, \mathrm{VE} / 67 / 23$, Edicto en que se amonesta a los sacerdotes confesores y misionarios a que asistan en las conferencias morales que se tuvieren en el Oratorio de la Congregación del Salvador del Mundo de esta Corte.

39 De la Madre de Dios 1736: 417-432.

40 Sánchez Belén 1996: 240-241.
} 
actuar con independencia de Toledo, algo inaceptable para Portocarrero que no descansó hasta lograr del papa Inocencio XII el reconocimiento de la preeminencia del arzobispo frente a las autoridades de la orden de Malta. ${ }^{41}$

Otro firme compromiso de la prelatura de Portocarrero lo constituyó su apoyo y reformas en la Universidad de Toledo, a la que encontró decadente a su regreso de Roma y para la que preparó un amplio programa de reformas e inversiones que garantizarán su supervivencia junto a una renovada calidad académica de la que al parecer carecía.

Pero con todo, el arzobispo y consejero de Estado no olvidó sus obligaciones con la monarquía hispánica en la persona del rey Carlos II, a quien por su condición de consejero le sugirió las esposas que debía tomar. Primero, como ya vimos, María Luisa de Orleans, reina que falleció en 1689. El consejero de Estado votó, tras una amplia deliberación, que la nueva esposa del rey fuera Mariana de Neoburgo:

[...] y consistiendo la dote más principal y de única consideración en la más prudente y probable esperanza de que se logre y asegure la sucesión que se desea con tan justas ansias, aquella Princesa deberá ser preferida cuyas virtudes y complexión natural se ajuste y proporcione más a los que tiene y de que está adornada Vuestra Majestad y en edad; y según estas circunstancias, juzgo por la más idónea a la Princesa Mariana y suponiendo las recomendables prendas del natural de esta Princesa, su dignísima educación y el cúmulo de regias virtudes, menospreciando las reflexiones e intereses dotales y el costoso viaje que ha de hacer a España concluyo en que no pueda Vuestra Majestad, salva su Real decencia, dar oídos a otro empleo. [...] Toledo 9 de abril de $1689 .{ }^{42}$

Con esta elección matrimonial comienza la última década del siglo XVII. La Casa Real con el rey Carlos II, la reina madre Mariana de Austria y la reina Mariana de Neoburgo será el escenario político donde irrumpa con fuerza la personalidad del arzobispo de Toledo, Luis Manuel Fernández Portocarrero, quien denunciará el estado de la monarquía con dos sonados memoriales dirigidos al rey, el primero, el 4 de enero de 1695, y otro el 28 de diciembre de 1696. En el primer memorial realiza un diagnóstico de la monarquía, señala como culpables directos a la camarilla de la reina y ya apunta criterios políticos para el buen gobierno de la nación donde se intuye una clara vocación política:

[...] seria en mi muy culpable omisión, no repetir a V.M. mis rendidas súplicas, para que esta gente salga de los Dominios de V.M. y en lo restante se dé planta conveniente, para que estos Reinos no se vean en el abandono, que hoy se consideran, reconociéndose destruidos, y arruinados no por el servicio de V.M. sino por su superfluidades, // y disposiciones indignas, estando

${ }^{41}$ ASV, Segreteria di Stato, Cardinalii, vol. 66, ff. 31-33. Madrid, 3 de marzo de 1701, carta del cardenal Portocarrero al secretario de Estado, cardenal Paulucci. En esta misiva, el cardenal recuerda la concordia del: «Breve de la Santidad de Inocencio XII de 12 de diciembre de 1698 sobre el modo y forma en que se ha de ejercer la jurisdicción delegada y ordinaria eclesiástica en los Prioratos de San Juan de Castilla y León, así por los Ministros de la Dignidad arzobispal de Toledo, como por los de la Prioral de San Juan y aprobando la Concordia hecha entre ambas sobre lo referido".

42 Baviera y Maura Gamazo 2004: vol. I, 72-75. atropellada, y vendida la Justicia, y despreciada la gracia, [...] debo suplicar a V. Majestad que de tantos y tan leales Vasallos, y Ministros como tiene V.M. de juicio, virtud, desinterés, y reputación, sepa V.M. si mis representaciones son justificadas, y la pública voz, y el // fundamento, con que todos claman por lo breve resolución, [...] Nuestro señor asista a V. Majestad, para que delibere, según es de su mayor servicio, y del Consuelo, y alivio, que necesitan sus leales y fieles Vasallos, y guarde a V. Majestad como hemos de menester, // y le suplicamos. ${ }^{43}$

Entre este memorial y el próximo transcurren dos años, en los cuales el cardenal Portocarrero ha pasado a un primer plano de la política nacional cuando tras fallecer la reina madre, y cumpliendo su voluntad, presenta al rey el primer testamento de sucesión en la persona del Príncipe Elector de Baviera, el infante José Fernando de Baviera. En diciembre de 1696 el cardenal Portocarrero considera al confesor del rey Pedro Matilla, a Pedro Núñez y al Almirante de Castilla culpables del deterioro de la monarquía, una vez más, Portocarrero se ofrece a salvarla:

[...] Muchos leales tiene V.M. a quien poderlo mandar, y los corazones de los que lo son, es el principal matrimonio de los reyes: el mío está a los Reales Pies de V.M. y todo es suyo, hasta los cálices para su // defensa en la última necesidad; pero primero es señor, que V.M. como Rey, como padre, como amparo, obre lo justo, y lo que debe a su grandeza, a su piadoso celo, y al atributo de justicia $\left[\ldots . . .{ }^{44}\right.$

El cardenal Portocarrero se convierte en el protagonista indiscutible en los últimos días de vida del rey Carlos II, logrando un nuevo testamento a favor del Príncipe Elector de Baviera, y tras su muerte, un definitivo testamento que entregaba la Corona de España al duque de Anjou, futuro Felipe V. El rey antes de morir el 1 de noviembre de 1700 dejó al cardenal Portocarrero como gobernador de todos los reinos con el mismo poder del monarca:

El Cardenal Portocarrero Arzobispo de Toledo, de mi Consejo de Estado me habéis servido y ayudado, en todo lo que he fiado a vuestro grande amor, en las mayores importancias, quiero y mando que en el ínterin, que N. S. dispone de mí, y llegue el caso de concederme la Salud que más convenga, o de que falte, y se abra mi testamento, gobiernes en mi nombre y por mí, todos mis Reinos así en lo Político como en lo Militar, y Económico en la misma forma que yo he hecho hasta aquí, y puedo hacerlo. ${ }^{45}$

Comenzaba un nuevo siglo con un nuevo rey, Felipe $\mathrm{V}$ de Borbón. El cardenal Portocarrero con plenos poderes es respaldado por el joven monarca, quien lo incorpora al despacho, nuevo gobierno por encima de juntas y consejos. Portocarrero asumirá nuevamente en dos ocasiones la regencia de España en la ausencia del rey Felipe V, decreto real del 31 de agosto de 1701 y del 5 de abril de 1702; el

43 BNE, Papeles curiosos manuscritos tomo 4, ff. 8v-12r. Memorial que el señor Portocarrero dio a Carlos II. Madrid, 4 de enero de 1695.

44 BNE, Papeles curiosos manuscritos, tomo 4, ff. $185 \mathrm{v}-214 \mathrm{r}$. Memorial que dio a S. M. El señor Cardenal Portocarrero. Madrid, 28 de diciembre de 1696 .

45 BNE, mss. 12964/20. Decreto de Carlos II nombrando Gobernador de estos Reino al Cardenal Portocarrero. Madrid, 29 de octubre de 1700. 
rey ha iniciado un viaje para celebrar cortes en Barcelona, contraer matrimonio con María Luisa de Saboya y trasladarse a los reinos de Italia.

En enero de 1703 el cardenal Portocarrero presenta su dimisión en sus responsabilidades de gobierno redactando un memorial muy clarificador del momento político de España en los últimos años del reinado del enfermo Carlos II, donde Portocarrero realiza un exhaustivo análisis de la situación en que se encontraban todos los Estados, su comportamiento y sus arbitrarias actuaciones para la continuidad de la monarquía hispánica:

[...] los mares y costas sin bajeles, los presidios y fronteras sin guarnición defensa, el reino sin milicias, armas ni gente, el Real Erario totalmente exhausto, el gobierno tiranizado y perturbado el orden del Estado enteramente sin conducta alguna; $y$ aunque se consideraban muchas las raíces de daño tan capital y universal, como era la debilísima [...] la multitud de nuevas fundaciones, exacciones y adquisiciones hechas por // regulares y eclesiásticos, la suma atenuación de los comercios y los empeños sucesivos inmensos de la Real Hacienda, que obligaban en las públicas urgencias a la opresión y exterminio de los vasallo [...]. ${ }^{46}$

Tras esta introducción desgrana las reformas que como primer ministro, Portocarrero llevó a cabo en la Casa Real, la Hacienda, Tributos, Defensa y muchas áreas donde se sintió desautorizado y halló la incomprensión para su proyecto de:

[...] reducir a un orden justo y cristiano el gobierno político del reino y con sana intención y amor los aconsejó. Y no siendo tampoco dable ceda por motivos que no alcanza a contrario dictamen sin nota de ambición y, lo que es insuperable, sin prejuicio de la propia conciencia, se halla absolutamente imposibilitado de continuar el real servicio en la ordinaria y universal conducta del gobierno [...]. ${ }^{47}$

Retirado del gobierno, mantuvo fidelidad al rey Felipe $\mathrm{V}$ y capacidad de crítica política desde el Consejo de Estado y autoridad moral desde el púlpito de la sede primada en Toledo. Algunos cronistas coetáneos quisieron ver en la actitud del arzobispo Portocarrero ante la entrada de las tropas austracistas en Toledo en el verano de 1706, una alta traición, que no fue tal, sino una vez más los comportamientos tácticos de un cardenal curtido en Roma, que supo salvar la integridad de los bienes y personas toledanas así como la integridad del estado eclesiástico. Portocarrero no entonó Te Deum, ni bendijo banderas y estandartes de las tropas del proclamado rey Carlos III:

Su conducta ante los acontecimientos de la proclamación del Archiduque Carlos como Rey de España en Toledo, cuando ya residía en la ciudad alejado de la política, ha sido distorsionada por los historiadores que se han basado en la equivocada apreciación que el Marqués de San Felipe hace de su actuación en la solemne ceremonia que se celebró en la Catedral con motivo de la bendición del estandarte austríaco en contra de D. Felipe V. El Cardenal Portocarrero no fue sujeto

${ }^{46}$ AMAE (Archives du Ministère des Affaires Étrangères), Correspondance politique, Espagne, t. 114, ff. 27r-38r Memorial del cardenal Portocarrero al secretario de estado de Francia, Torcy sobre los males de la Monarquía Hispánica. Madrid, 18 de enero de 1703.

47 Ídem. activo, no fue él quien cantó el Te Deum de acción de gracias sino el Canónigo D. Juan de Pinillos como Preste oficiante vestido con capa pluvial muy rica, acompañado de D. Juan Pimentel, Vice-deán, y de D. Fernando Merino, Tesorero. ${ }^{48}$

La correspondencia entre el cardenal Portocarrero y el papa Clemente XI desvela aspectos desconocidos de los acontecimientos de 1706 distorsionados posteriormente. Extraemos este fragmento de la misiva de julio de 1707, donde el arzobispo narra los acontecimientos bélicos que asedian a Toledo, la prudencia y tacto del cardenal y los graves daños ocasionados por las tropas aliadas:

[...] Notorio es a Vuestra Santidad y al mundo la grande irrupción y lamentables sucesos, que en la campaña del año pasado de 1706 experimentaron estos católicos Reinos, y especialmente este arzobispado, manteniendo muchos días dos poderosos ejércitos en las cercanías de Madrid, y de su capital Toledo, en cuyo tiempo, no hubo género de mal que no experimentase nuestra desgracia, ni fatalidad que no llorasen nuestro ojos $[\ldots]{ }^{49}$

Con un ejército amenazante en las puertas de Toledo y decido a intervenir si no se cumplen sus exigencias, de no ser por una demostración de recibimiento fingido, la suerte de esa ciudad y sus vecinos hubiera sido otra. El cardenal Portocarrero restituye rápidamente las oraciones pro tempore belli a favor de Felipe $\mathrm{V}$, y una vez más acude en ayuda del monarca con oraciones, materiales y dinero, corriendo un enorme riesgo personal y una amenaza seria sobre Toledo en palabras del marqués de las Minas: "Yo no necesito de hacer presente a Vuestra Eminencia el inminente peligro en que se hallan sus ovejas de experimentar el último rigor y esa ciudad su total ruina». ${ }^{50}$

Superada esta grave crisis militar, el cardenal Portocarrero participa activamente en las alegrías de la victoria de Almansa, en el nacimiento y bautismo del príncipe Luis Fernando en 1707, y su juramento como Príncipe de Asturias en 1709, aún más, será la voz de los Grandes en apoyo del joven rey cuando su abuelo, el rey de Francia Luis XIV le retire la confianza. No obstante, el cardenal Portocarrero es una voz independiente en el Estado centralista y regalista Borbón, no dudando en mostrar públicamente su desacuerdo con Felipe $\mathrm{V}$ en la ruptura de relaciones con la Santa Sede de Clemente XI.

En aquel verano de 1709 , con setenta y cuatro años, eran muchos los que deseaban su retorno a la primera línea política ante la crisis institucional con Roma y Versalles y el ritmo de la Guerra de Sucesión, pero al cardenal Portocarrero le quedaban días de vida. En agosto cayó enfermo de erisipela y se le llegó a dar el viático, pero para sorpresa de muchos se recuperó. Una nueva recaída le postró definitivamente en cama en su casa junto a la parroquia de los santos Justo y Pastor de Madrid, hasta su muerte el sábado 14 de septiembre. La Gaceta de Madrid

48 García Fernández 2013: 1290-1291.

49 ASV, Segretaria di Stato, Cardinalii, vol. 72, ff. 239-250. Cardenal Portocarrero al Papa Clemente XI. Madrid, 19 de julio de 1707.

50 AMT (Archivo Municipal de Toledo). LAC, 127, Carta del Marqués de las Minas, Guadalajara, 27 de julio de 1706, p. 374v, apud Rodríguez González 2006: 204. 
lo contó así:

Sábado 14, a las cinco de la mañana, murió en esta Corte, con Universal sentimiento, el señor cardenal, D. Luis Manuel Portocarrero, Arzobispo de Toledo, Primado y Protector de las Españas, y Obispo de Palestina [sic] como uno de los Cardenales Obispos más antiguos, que componen el Sacro Colegio, de edad de 74 años. Fue hijo de los Condes de Palma, Grandes de España. Siendo Deán muy ejemplar de aquella Santa Iglesia le creó Cardenal el Papa Clemente IX, el año de 1669 y el de 1677 le presentó para este Arzobispado el señor Rey Carlos Segundo. Fue Virrey de Sicilia, Embajador Extraordinario de Roma, Teniente General de la Mar, del Consejo de Estado, y por dos veces único Gobernador de España, habiendo logrado las más íntimas confianzas de sus Majestades, a quien correspondió con singularísimo celo, amor y desinterés [...] Mandose enterrar sin fausto en su Santa Iglesia Primada de Toledo. ${ }^{51}$

Y esa fue su última voluntad, siendo trasladado a la catedral de Toledo donde fue enterrado con toda solemnidad bajo una lápida a ras de suelo, que personalmente hizo esculpir y trasladar desde Roma para tan señalado día. Escogió el mismo epitafio que conoció y leyó en la tumba del cardenal Antonio Barberini en Roma, Hic iacet pulvis cenit el nihil. Y dejó preparado un extenso e interesante testamento donde refleja su pensamiento político, las personas y lugares que marcaron su vida, su madre la marquesa de Almenara, su sobrino el conde de Palma, los reyes Carlos II y Felipe V, los pontífices Clemente $\mathrm{X}$ e Inocencio XI, y su paso por Palma del Río, Toledo, Madrid, Roma, Asís, Loreto y otros puntos del mundo con los que mantuvo una relación eclesial como el Norte de África, América o centro Europa. Un político y eclesiástico de la Edad Moderna con una iconografía propia.

\section{SU IMAGEN}

No fue casual la elección de ese epitafio para el sepulcro del cardenal que fuera tres veces regente de España. Luis Manuel Fernández Portocarrero y Guzmán tuvo plena conciencia de su paso a la historia, todavía más, trabajó para reformular la Historia de España promoviendo un círculo de jóvenes historiadores y otras ciencias, conocidos como novatores, que reescribieran a la luz de la investigación documentada. ${ }^{52}$

En el momento que es nombrado cardenal Príncipe de la Iglesia comienza a crearse su imagen, que consideramos empieza por la elaboración de su escudo de armas, un proyecto de visualización de la imagen del poder, tal como ha estudiado el profesor Enrique Soria. ${ }^{53}$ Un escudo de armas donde reúne los blasones de los linajes PortocarreroBocanegra-Mendoza y Luna bajo el capelo cardenalicio y

51 La Gazeta de Madrid, 17 de septiembre de 1709.

52 Gil Fernández et al. 2004: 12: "¿Dónde hinca sus raíces la Ilustración española? En los finales del siglo XVII, en aquel movimiento conocido de los novatores, que se ocupó tanto de una nueva filosofía, cuanto de ciencia o de renovadoras maneras de hacer historia, todo lo cual arrancaría, por citar una fecha de referencia, de 1680. [...] algunos intelectuales, tímidamente habían ido abriendo las puertas a la innovación, que dan frutos en tiempos de Felipe $\mathrm{V}$ (creación de las Reales Academias de la Lengua y la Historia, y otras instituciones culturales)».

53 Soria Mesa 2011: 7. rodeado de quince banderas, privilegio concedido por los Reyes Católicos al VII señor de Palma y a sus descendientes. Su nombramiento como arzobispo le permitirá incluir la mitra, el báculo y la cruz arzobispal. Del poeta Horacio, en versos latinos toma su lema: Evehit Ad Deos Terrarum Domino Palmaque Nobilis. Será pues esa palma, su referencia a su origen, Palma del Río. Tras la concesión de la medalla de la orden francesa del Espíritu Santo, ésta formará parte del escudo.

Las primeras estampas o imágenes artísticas sobre el cardenal Portocarrero obedecen a la necesidad de incluirlo en la relación de cardenales, Effigies, nomina et cognomina S. D. N. Inocentii PP XI et RR S. R. E. Card. Nunc viventium... cuadro de imágenes de todos los cardenales vivos en ese momento. Albert Clouwet realiza la estampa que reproduce el afamado grabador Giovanni Giacomo de Rossi, siendo impreso en Roma entre 1669 y 1676. Aquí aparece el cardenal con su primer escudo que será representado a lo largo de toda su vida en todos los ámbitos políticos, eclesiásticos, patrocinios y espacios domésticos.

Su estancia en Roma quedó registrada por dos magníficos óleos, uno pintado por Giovanni Battista Gaulli, y otro del pincel del holandés Jacob Ferdinand Voet. En los dos cuadros el cardenal revestido de la púrpura y bonete, mira fijamente, con un aire distinguido y con suma naturalidad. El gusto por las medallas conmemorativas también tiene dos registros en Roma. El año jubilar de 1675 encarga la medalla que recuerde la clausura de la puerta santa de la basílica de Santa María la Mayor, siendo papa Clemente X, tal como se acuñó en el anverso, dejando el reverso para resaltar al presbítero cardenal Portocarrero.

Tras su éxito militar como virrey de Sicilia entre 1677 y 1678 y recién nombrado embajador extraordinario en Roma manda el diseño de una medalla laudatoria al mejor artista del momento, el italiano Giovanni Martino Hamerani, quien funde en bronce una pieza extraordinaria donde en el anverso reproduce el busto del cardenal con bonete, con todos sus títulos de arzobispo de Toledo, consejero de Estado, virrey y capitán general de Sicilia, teniente general de la mar y embajador extraordinario ante Inocencio XI, y en el reverso el puerto de Mesina con galeras y cañones, pedestal con escultura alegoría de la Fama, genios portando la cruz arzobispal, mitra y báculo, y su escudo de armas. ${ }^{54}$

A su regreso a España en 1679 para ocupar la sede primada de Toledo será objeto de crónicas, panegíricos y quintillas para inmortalizar su entrada en el arzobispado. Su asistencia al auto de fe en Madrid en junio de 1680 quedó reflejada en el cuadro de Francisco Rizzi, Auto General de $\mathrm{Fe}$ que se conserva en el Museo del Prado. Nicolás de Bussi realiza una escultura del busto del cardenal que se encuentra en el Museo de Santa Cruz de Toledo.

Pero la imagen del cardenal Portocarrero se hará internacional a partir de 1700 cuando logra que el rey Carlos II elija como sucesor de la Corona de España al duque de Anjou, Felipe $\mathrm{V}$ de Borbón. Todos atribuyen al cardenal Portocarrero la redacción del último testamento de Carlos II, por tanto la imagen de Portocarrero es enaltecida en Francia y vilipendiada en los estados aliados en la Guerra

\footnotetext{
54 Existen ejemplares de esta medalla en varios museos, ver Museo
} Lázaro Galdiano. 
de Sucesión española. Henry de Favanne pinta en 1704 un soberbio cuadro donde el cardenal aparece idealizado como un cardenal patricio de cabellos plateados, alto y sublime como testigo en la obra España ofrece su Corona al duque de Anjou:

El Museo Nacional de los palacios de Versalles y de Trianon posee entre sus fondos una pintura de Henry de Favanne realizada por sugerencia de la princesa de los Ursinos en 1704 y que muestra al duque de Anjou (el futuro Felipe V), presentado por Francia y recibiendo de manos de España la corona real, en presencia del cardenal Portocarrero [...]..$^{55}$

El cardenal Portocarrero es considerado en las artes francesas el hombre que ha hecho posible el advenimiento de la Casa de Borbón en España, y por tanto, es tratado como hombre de Estado, máxime desde el momento y hora en que el rey de Francia Luis XIV hace entrega del collar de comendador de la orden del Sancti Spiritu, la más importante condecoración del reino galo. El cardenal Portocarrero es representado en los grandes momentos del rey Felipe V, su llegada a Madrid, ceremonia de juramento en San Jerónimo, bodas reales, en el nacimiento de Luis I, entrega del Toisón de Oro, el bautismo y jura del Príncipe de Asturias y en la galería de personajes ilustres de Francia. ${ }^{56}$

Pero en los países del bando aliado en la Guerra de Sucesión española, el cardenal Portocarrero es representado satírica y agresivamente. La sátira lo representa agarrando la vaca de España para ser ordeñada y dar su leche a Luis XIV. Portocarrero es objeto de múltiples representaciones donde se le compara con un hombre mitad eclesiástico y mitad noble, un sujeto encarcelado, un manipulador en la linterna mágica o es pintado cual si fuera un diablo con forma de serpiente, y en ocasiones, se le presenta simbólicamente como un capelo que oculta el testamento de Carlos II. Pieter Schenk realiza un grabado del cardenal Portocarrero, que se conserva en el Rijksmuseum, en el esplendor juvenil de mirada penetrante pero con una cartela donde se compara en tono jocoso con Richelieu y Mazarino, es evidente que este cuadro fue pintado en el transcurso de la Guerra de Sucesión, como también lo fue una crítica aplastante donde el cardenal Portocarrero contempla la batalla de Malplaquet el 11 de septiembre de 1709, días antes de su muerte tal como se hace constar en el texto del grabado. ${ }^{57}$

La imagen del cardenal Portocarrero fue un clásico durante siglos. Historiadores y escritores de la llustración, el Romanticismo y las nuevas artes del siglo XX, como el cine, crearon un personaje distorsionado entre la intriga y la ambición. Luis Manuel Fernández Portocarrero Bocanegra Mendoza Luna y Guzmán bien merece una tesis doctoral.

\section{CONCLUSIONES}

Sin duda alguna, las últimas investigaciones sobre la vida, obra e imagen que acabamos de ofrecer sobre Luis Manuel Fernández, cardenal Portocarrero (1635-1709), aportan una importante revisión biográfica sobre tan sobresaliente

\footnotetext{
55 Serrano Martín 2004: 9.

56 Todas estas estampas se conservan en la BNF, colección Gallica.

57 Todas estas estampas se pueden consultar en el portal digital Europeana.
}

eclesiástico y político. La construcción de la historia del cardenal se creó a partir de una serie de historiadores coetáneos con posiciones diferentes en el transcurso de la Guerra de Sucesión, es ahí donde radica la proyección posterior del cardenal, circunscrita a los acontecimientos ocurridos entre 1699 y 1705, es decir, conflictos internos por la sucesión, elaboración del testamento, entronización de Felipe $\mathrm{V}$ de Borbón y gobierno de Portocarrero en el transcurso de los primeros años de la Guerra de Sucesión. Es fácil comprender que toda la trayectoria del cardenal quede relegada a este espacio de tiempo y que algunos desearon quedara registrado como ambicioso, oportunista, intrigante, manipulador y carente de capacidad intelectual y política para haber llegado donde llegó. Eso mismo se ha dicho en Historia de muchos de nuestros personajes de referencia.

La historiografía mayormente se ocupó de este período político de la historia de España, pero descuidó la relación del cardenal Portocarrero en los territorios eclesiásticos y culturales, despreciando una oportunidad de conocer a un hombre que influyó en gran medida en la conducción pastoral de la Iglesia y en la renovación de la cultura española con su apoyo decidido a historiadores, médicos, literatos, artistas e intelectuales que ya anunciaba un nuevo tiempo de pre-llustración.

Por esta misma razón, la trayectoria vital del cardenal Portocarrero careció de importancia para los historiadores, prácticamente desde el s. XVII, trasladándose errores en sus datos biográficos que han llegado hasta nuestros días sin ser corregidos. Los trazados o notas biográficas han atrapado datos mínimos y desgraciadamente equivocados. Así se ha podido afirmar que nació entre los años de 1628 a 1635; ello fuerza a que muera con diferentes edades. Sobre su familia, se ha dicho era hijo de los condes de Palma, cuando únicamente fue nieto, hermano y tío de los condes de Palma. A este último, su sobrino el $\mathrm{V}$ conde, algunos lo ubican como su hermano. En este sin sentido, se ha escrito que era hijo de la señora que aparece en el cuadro de las Meninas, Marcela de Ulloa. Sobre sus apellidos, lo han llamado Moscoso-Osorio, del todo imposible. Y así, una larga lista de ideas confusas, como ir en 1675 a recoger el capelo y conocer a la Princesa de Ursinos, cuando ello tuvo lugar en 1670. Estos errores se repiten en los trabajos de más de un historiador, en muchas ocasiones, por la simple razón de dar por válido una información no contrastada y tomada literalmente de otras obras publicaciones.

A su vez, se pertrecharon unos perfiles psicológicos que difícilmente podían corresponder con un hombre que alcanzó todo el poder de su tiempo, como ha considerado el historiador Luis Antonio Ribot García en sus numerosas investigaciones sobre la figura del cardenal Portocarrero. En el libro El arte de gobernar, concluye:

El cardenal Portocarrero fue una figura clave. Es curioso que la mayoría de las informaciones sobre él insistan en su escasa capacidad o su falta de formación y cultura. La realidad es que en los últimos años del reinado de Carlos II jugó un destacadísimo papel político, siendo líder indiscutible del Consejo de Estado y el personaje más determinante en el resultado final de la sucesión. ${ }^{58}$

\footnotetext{
58 Ribot García 2006: 260
} 
El profesor Ribot García en su discurso de ingreso en la Real Academia de la Historia desmonta la información transmitida sobre el cardenal Portocarrero por los mal llamados historiadores coetáneos, los historiadores de la Literatura y los mitos, para terminar afirmando:

Los estudios cada vez más frecuentes sobre el reinado nos presentan, por el contrario, una clase política de bastante más talla de cuanto se había creído. Fue más su pragmatismo, o mejor aún, su patriotismo, el que les guió en la hora decisiva. ${ }^{59}$

Concluimos pues, que el cardenal Luis Manuel Fernández Portocarrero y Guzmán no solo fue el hombre clave en la transición política de la dinastía Austria a la dinastía Borbón sino que per se reúne el cursus honorum de un eclesiástico que alcanzó desde una coadjutoría, la púrpura, desde Sumiller de Cortina a regente de España en tres ocasiones, siendo la máxima expresión de la unión del trono y el altar puestos al servicio de la monarquía católica hispánica.

\section{SIgLAS UTILIZADAS}

ACT Archivo Capitular de Toledo

ADT Archivo Diocesano de Toledo

AGS Archivo General de Simancas

AHPZ Archivo Histórico Provincial de Zaragoza

AMAE Archivo Ministerio de Asuntos Exteriores (París)

APNP Archivo de Protocolos Notariales de Posadas

ASV Archivo Secreto Vaticano

BNE Biblioteca Nacional de España

\section{FUENTES}

Cabezas, J. 1676. Relación verdadera, de la función que se hizo en Roma, víspera de la natalidad de N. Señor y Salvador lesuchristo de 1675. Por el eminentísimo señor Cardenal Porto-Carrero de título de Santa Sabina, hijo de la Casa de Palma como legado á Latere... Sevilla.

Chacón, A. y Oldoini, A. 1677. Vita et res gestae Pontificum Romanorum et S.R.E. Cardinalium ab initio nafcentis Ecclefiae ufque ad Clementem IX. POM. Ramae: Philippi et Ant. Rubeis.

De la Madre de Dios, fray A. 1736. Vida histórico-panegírica de la venerable madre y penitentísima Virgen Mariana Francisca de los Ángeles... Madrid.

Di Cannara, G. 1780. Notizie raccolte dalla storia della Sacra Porziuncula o sia Santa María... Asís.

Escolano y Ledesma, D. 1669. Memorial a la Reyna Nuestra Señora.. sobre el uso de la silla en la procesión del corpus. Granada.

\section{BIBLIOGRAFÍA}

Barrio Gozalo, M. 2009. "La Embajada de España ante la corte de Roma en el siglo XVII ceremonial y práctica del buen gobierno». Studia Historica. Historia moderna 31: 237-273.

Barrio Gozalo, M. 2010. El clero en la España moderna. Córdoba: CSIC.

Barrio Gozalo, M. 2013. La embajada de España en Roma durante el reinado de Carlos II (1665-1700). Universidad de Valladolid.

Baviera, Príncipe A. de y Maura Gamazo, G. 2004. Documentos inéditos referentes a las postrimerías de la Casa de Austria en España.
Madrid: Centro de estudios políticos y constitucionales, Real Academia de la Historia.

Burillo Loshuertos, J. 1997. «Don Diego Escolano y Ledesma». Anales de Derecho 15: 124.

Carrió Invernizzi, D. 2008. El gobierno de las imágenes. Ceremonial y mecenazgo en la Italia española segunda mitad del siglo XVII. Madrid: Iberoamericana.

Casteñeda Becerra, A. M. 2006. «El cardenal Portocarrero. Un retrato de Pedro de Moya». Cuadernos de arte de la Universidad de Granada 37: 403-412.

De Bernardo Ares, J. M. (coord.). 2013. El Cardenal Portocarrero y su tiempo (1635-1709), biografías estelares y procesos influyentes. León: Csedhistoria.

Domínguez Rodríguez, J. M. 2014. «El cardenal José Sainz de Aguirre en el contexto cultural romano de finales del siglo XVII». Berceo 166: 31-62.

Esténaga y Echevarría, N. 1929. El Cardenal Aragón (1626-1677). París: imprenta E. Desfossés.

Fernández Collado, A. 2001-2002. «Los informes de visita ad limina del cardenal Portocarrero, arzobispo de Toledo». Anthologica annua 48-49: 49-102.

García Fernández, A. 2013. Toledo entre Austrias y Borbones: su aportación al inicio de la Guerra de Sucesión (1690-1706). Tesis doctoral dirigida por el Dr. José Cepeda Gómez. Universidad Complutense de Madrid.

Gil Fernández, L. et al. 2004. La cultura española en la Edad Moderna. Barcelona: Ed. Istmo.

Gligora, F. y Catanzaro, B. 2015. /l Giubileo Segni, Simboli, Riti. Roma.

López-Guadalupe Muñoz, M. L. 2010. «Jurisdicción real y jurisdicción eclesiástica: el auxilio de las fuerzas en la Granada del seiscientos», en J. J. Lozano Navarro (coord.), Violencia y conflictividad en el universo barroco: 301-344. Granada: Editorial Comares Historia.

Lozano Navarro, J. J. 2010. «La Monarquía española y la sede vacante de 1676». Tiempos Modernos, Revista Electrónica de Historia Moderna 7 (20): 1-27.

Lozano Navarro, J. J. 2013. "Valido defenestrado, embajador despreciado. Algunas reflexiones sobre la deslegitimación política en torno al cardenal Juan Everardo Nithard». Kripton 2: 19-31.

Marqués, J. M. 1983. La Santa Sede y la España de Carlos II: la negociación del nuncio Millini 1675-1685. Roma: Iglesia Nacional de España.

Peña Izquierdo, A. R. 2004. La Casa de Palma. La familia Portocarrero en el gobierno de la Monarquía Hispánica (1665-1700). Córdoba: Universidad de Córdoba.

Ribot García, L. A. 2002. La Monarquía Hispánica y la Guerra de Mesina (1674-1678). Madrid: Actas Editorial.

Ribot García, L. A. 2006. El arte de gobernar, estudios sobre la España de los Austrias. Madrid: Alianza Editorial.

Ribot García, L. A. 2010. Orígenes políticos del testamento de Carlos II. La gestación del cambio dinástico en España, discurso leído el 17 de octubre de 2010 en la recepción pública del Excmo. Sr. D. Luis Antonio Robot García y contestación por el Excmo. Sr. D. Luis Miguel Enciso Recio. Madrid: Real Academia de la Historia.

Rodríguez González, A. 2006. Los primados de Toledo 1666-1709. Toledo: Ediciones Parlamentarias de Castilla-La Mancha.

Sánchez Belén, J. A. 1996. La política fiscal en Castilla durante el reinado de Carlos II. Madrid: Siglo veintiuno de España Editores.

Serrano Martín, E. (ed.). 2004. Felipe V y su tiempo. Zaragoza: Institución Fernando El Católico.

Soria Mesa, E. 2011. «La imagen del poder. Un acercamiento a las prácticas de visualización del poder en la España moderna». Historia y Genealogía 1: 5-10.

\footnotetext{
59 Ibídem 2010: 138-139.
} 